\title{
CHARACTERIZATION OF INTERNAL FRICTION OF Fe-30Mn-6Si-5Cr
}

\author{
T.S. Chou ${ }^{1}$, H.C. $\mathrm{Lin}^{2}$, K.M. $\mathrm{Lin}^{2}$ and S.K. Wu ${ }^{3}$ \\ ${ }^{1}$ Steel and Aluminum R \& D Department, China Steel Corporation, Kaohsiung, Taiwan 812, \\ Republic of China ${ }^{2}$ Department of Materials Science, Feng Chia University, Taichung, Taiwan 400, \\ Republic of China ${ }^{3}$ Institute of Materials Science and Engineering, National Taiwan University, \\ Taipei, Taiwan 106, Republic of China
}

(Received July 29, 1999)

(Accepted in revised form September 28, 1999)

Keywords: Iron based shape memory alloy; Internal friction; Martensitic transformation

\section{$\underline{\text { Introduction }}$}

Fe-Mn-Si iron-based shape memory alloys have attracted much attention due to their low cost and excellent workability. Many papers [1-4] reported that Fe-Mn-Si alloys, containing 28 to 34 wt\% Mn and 4 to $6.5 \mathrm{wt} \% \mathrm{Si}$, exhibit a nearly perfect shape memory effect (SME). Moreover, $\mathrm{Cr}$ and $\mathrm{Ni}$ have recently been added to the $\mathrm{Fe}-\mathrm{Mn}-\mathrm{Si}$ alloys resulting in an improved $\mathrm{SME}$ and corrosion resistance [5,6]. Unlike TiNi and $\mathrm{Cu}$-based shape memory alloys, Fe-Mn-Si alloys exhibit a non-thermoelastic martensitic transformation. Their SME comes from the reverse transformation of stress-induced $\epsilon$-martensite (HCP structure) into $\gamma$-parent austenite (FCC structure) on heating [1]. In the past decade, extensive studies for the Fe-Mn-Si alloys have been conducted on the transformation behaviors [1,7-9], physical properties [7-10] and composition dependence of SME and corrosion resistance [5,11-13]. Much effort has also been devoted to their practical applications, especially on the "heat-to-shrink" pipe coupling [14]. More recently, thermo-mechanical training, in which the alloys are treated by the repetition of small amounts of tensile deformation at room temperature, followed by subsequent annealing at $500 \sim 600^{\circ} \mathrm{C}$, has been reported to improve effectively the SME of Fe-Mn-Si alloys [15-17]. To extend their applications, a better understanding of Fe-Mn-Si shape memory alloys is necessary, including their shape memory characteristics, phase transformation temperatures and thermo-mechanical treatments. Owing to its high sensitivity on constitutional structures, internal friction measurement has been used to investigate the martensitic transformations for thermoelastic alloys [18,19] and ferrous alloys [20,21]. In our previous paper [7], the internal friction characteristics due to $\gamma \leftrightarrow \epsilon$ martensitic transformation have been examined by simple heating and cooling cycles. In the present study, the characterization of internal friction with the change in deformation states on an Fe-30Mn-6Si-5Cr shape memory alloy is investigated. In addition, the effect of thermo-mechanical training on the SME of this alloy is also discussed.

\section{Experimental Procedure}

The vacuum melting technique was employed to prepare the Fe-30Mn-6Si-5Cr (wt \%) alloy. The as-cast ingot was homogenized at $1100^{\circ} \mathrm{C}$ for 24 hours and then hot-rolled into 5-mm thickness by using a 
(a)

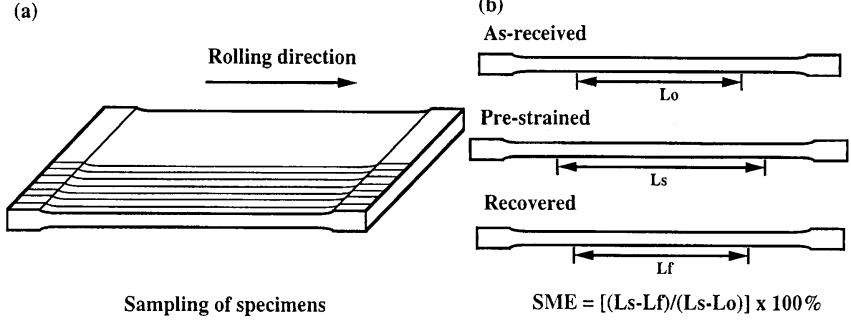

Figure 1. Schematic diagrams illustrate (a) sampling method and (b) the evaluation of shape memory effect.

two-high hot-rolling mill. Specimens for SME, internal friction, X-ray diffraction and tensile test were carefully machined from this hot-rolled plate. The SME was examined by a tensile test. Specimens were tensile-strained with a variety of strain and then reheated to $500^{\circ} \mathrm{C}$ for $10 \mathrm{~min}$. The related SME was then calculated. Figure 1 illustrates the sampling method and the evaluation of SME. To determine the effect of thermo-mechanical training on the SME, specimens were treated by the repetition of a $5 \%$ tensile strain and subsequent heating up to $500^{\circ} \mathrm{C}$ for several times. The internal friction test was carried out using a SINKU-RIKO $1500 \mathrm{M} / \mathrm{L}$ series inverted torsion pendulum in the temperature range from $-150^{\circ} \mathrm{C}$ to $500^{\circ} \mathrm{C}$. The measuring frequency was about $1 \mathrm{~Hz}$, and the heating and cooling rate was kept at $2^{\circ} \mathrm{C} / \mathrm{min}$. The recording of data was completely automatic. A digit computer carried out the calculation and plotted the curve of internal friction $\mathrm{Q}^{-1}$ versus temperature. Thus, the results obtained have a rather good resolution. X-ray diffraction analysis was performed at room temperature with the Siemens D500 X-ray diffractometer using $\operatorname{MoK} \alpha$ radiation. Meanwhile, a Shimazu tensile tester was applied to measure the mechanical properties of tested specimens.

\section{Results and Discussion}

Table 1 presents the results of SME test for the specimens with a variety of pre-strain. As shown in the Table 1 , the $2 \%$ pre-strained specimen can exhibit a nearly perfect SME. Nevertheless, the SME decreases rapidly with increasing pre-strain applied. This feature indicates that the $\mathrm{Fe}-30 \mathrm{Mn}-6 \mathrm{Si}-5 \mathrm{Cr}$ alloy could be favored for application only under a small strain condition, say $5 \%$ for the as hot-rolled specimen. As mentioned above, the thermo-mechanical training can improve effectively the SME of Fe-Mn-Si alloys. This phenomenon is also confirmed in this study. Table 2 presents the effect of thermo-mechanical training on the SME for the 5\% pre-strained condition. As can be seen in Table 2, the SME is considerably improved from $75 \%$ up to $86 \%$, along with the cyclic training number increased from the first to the 4th cycle.

Figure 2 shows the plots of internal friction $\mathrm{Q}^{-1}$ versus temperature for the $\mathrm{Fe}-30 \mathrm{Mn}-6 \mathrm{Si}-5 \mathrm{Cr}$ alloy of the as hot-rolled as well as $2 \%, 5 \%$ and $10 \%$ pre-strained specimens. In Fig. 2, there is a sharp internal friction peak at around $120^{\circ} \mathrm{C}$ for the as hot-rolled specimen. For the $2 \%$ pre-strained specimen, the internal friction peak at $120^{\circ} \mathrm{C}$ is broadened. By increasing the pre-strain to $5 \%$, a very wide internal friction spectrum with a peak temperature of $200^{\circ} \mathrm{C}$ can be observed. Furthermore, for the $10 \%$

TABLE 1

Effect of the Pre-Strain on the SME

\begin{tabular}{lccccc}
\hline Pre-strained $\%$ & 2 & 5 & 10 & 12 & 15 \\
\hline SME $\%$ & 99 & 75 & 39 & 29 & 18 \\
\hline
\end{tabular}


TABLE 2

Effect of Thermo-Mechanical Training on the SME for 5\% Pre-Strained Condition

\begin{tabular}{lcccc}
\hline Cyclic training number & 1 & 2 & 3 & 4 \\
\hline SME $\%$ & 75 & 77 & 82 & 86 \\
\hline
\end{tabular}

pre-strained specimen, there is another obvious internal friction peak appearing at $300^{\circ} \mathrm{C}$. Under a careful analysis, these internal friction spectra could be classified into three peaks which locate at around $120^{\circ} \mathrm{C}, 200^{\circ} \mathrm{C}$ and $300^{\circ} \mathrm{C}$. The wide internal friction spectrum of the $5 \%$ pre-strained specimen just comes from the combination of these three peaks. Throughout the decomposition of the internal friction spectrum, the $\mathrm{Q}^{-1}$ values of $120^{\circ} \mathrm{C}, 200^{\circ} \mathrm{C}$ and $300^{\circ} \mathrm{C}$ peaks are found to be $6.2 \times 10^{-3}, 9.1 \times$ $10^{-3}$ and $4.6 \times 10^{-3}$, respectively. The effect of thermo-mechanical training on the internal friction for the 5\% pre-strained condition is also illustrated in Fig. 3. As can be seen in Fig. 3, the maximum height of the $200^{\circ} \mathrm{C}$ peak increases with increasing cyclic training number.

To analyze and explain the related features and physical meaning of the internal friction spectra observed in Figs. 2 and 3, X-ray diffraction was carried out on both the as hot-rolled and 5\% pre-strained specimens. Figure 4 (a) and (b) show the X-ray diffraction spectra of the as hot-rolled and $5 \%$ pre-strained specimens, respectively. It reveals that the stress-induced $\epsilon$-martensite is present in the pre-strained specimen, but not in the as hot-rolled specimen. Hence, the $120^{\circ} \mathrm{C}$ peak found in the as hot-rolled specimen is ascribed to the reverse transformation of the thermal-induced $\alpha^{\prime}$-martensite (BCT structure) into the parent austenite phase. On the other hand, the $200^{\circ} \mathrm{C}$ peak could be attributed to the reverse transformation from the stress-induced $\epsilon$-martensite to the parent austenite phase. As shown in Fig. 3, the maximum height of the $200^{\circ} \mathrm{C}$ peak increases with increasing cyclic training number. Two reasons may account for this feature. First, the volume fraction of the stress-induced $\epsilon$-martensite is increased, and second, the $\epsilon$-martensite becomes easily reverse transformed into the parent austenite phase after thermo-mechanical training. Both of the above conditions will also improve the SME. Jiang et al. $[16,17]$ reported that, with the aid of autocatalytic activation mechanism, much more preferentially oriented and refined $\epsilon$-martensite plates would be generated after cyclic thermomechanical training. On heating, these preferentially oriented and refined $\epsilon$-martensite plates can easily

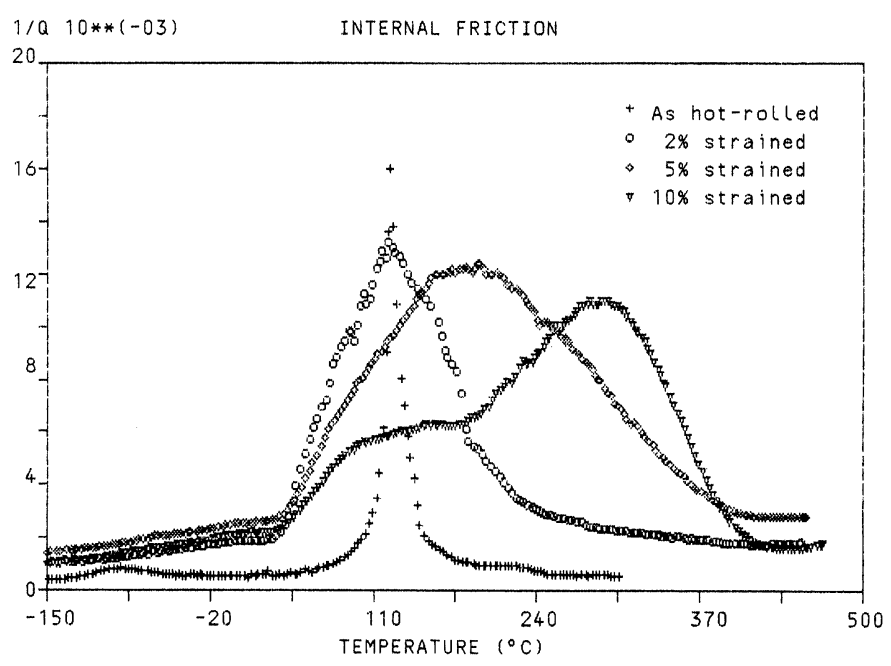

Figure 2. Internal friction of the as hot-rolled and different pre-strained Fe-30Mn-6Si-5Cr specimens. 


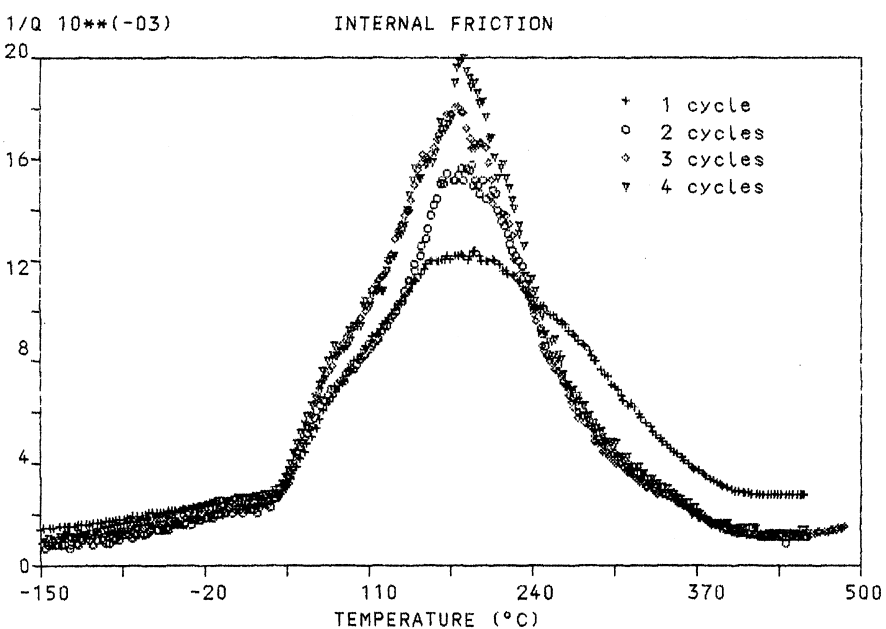

Figure 3. Internal friction of the cyclic thermo-mechanical training $\mathrm{Fe}-30 \mathrm{Mn}-6 \mathrm{Si}-5 \mathrm{Cr}$ specimen.

reverse transform into the parent austenite phase. Fig. 3 also indicates that the maximum height of the $200^{\circ} \mathrm{C}$ peak is increased while its peak temperature is slightly reduced after more cyclic thermomechanical training. These features are in good agreement with the fact that a higher volume fraction of the preferentially oriented and refined $\epsilon$-martensite, which can easily reverse transform into the parent austenite phase, has been generated after more cyclic thermo-mechanical training. Therefore, the SME is improved, as shown in Table 2.

As seen in Fig. 2, a remarkable internal friction peak appears at around $300^{\circ} \mathrm{C}$ for the $10 \%$ pre-strained specimen. The higher the pre-strain, the more obvious the $300^{\circ} \mathrm{C}$ peak is. Since the dislocation density increases with increasing plastic deformation, the $300^{\circ} \mathrm{C}$ peak is easily ascribed to the dislocation relaxation occurring in the deformed specimen. For confirmation, the internal friction test was further made on a heavily cold-rolled specimen with a $28 \%$ thickness reduction, and the result is shown in Fig. 5. Carefully examining the internal friction spectra shown in Figs. 2 and 5, we can easily find that the maximum height of the $300^{\circ} \mathrm{C}$ peak increases with increasing plastic deformation,

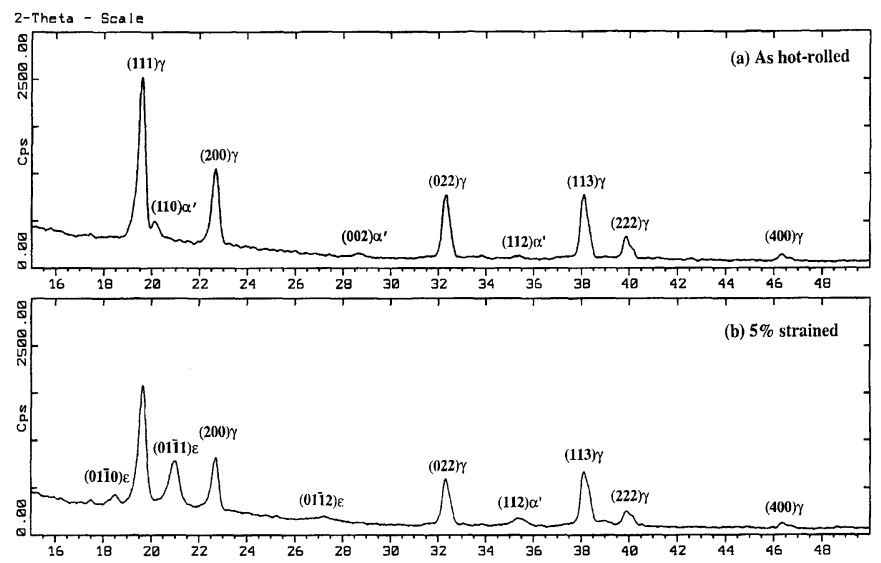

Figure 4. The X-ray diffraction (XRD) spectra of the as hot-rolled and 5\% pre-strained samples. 


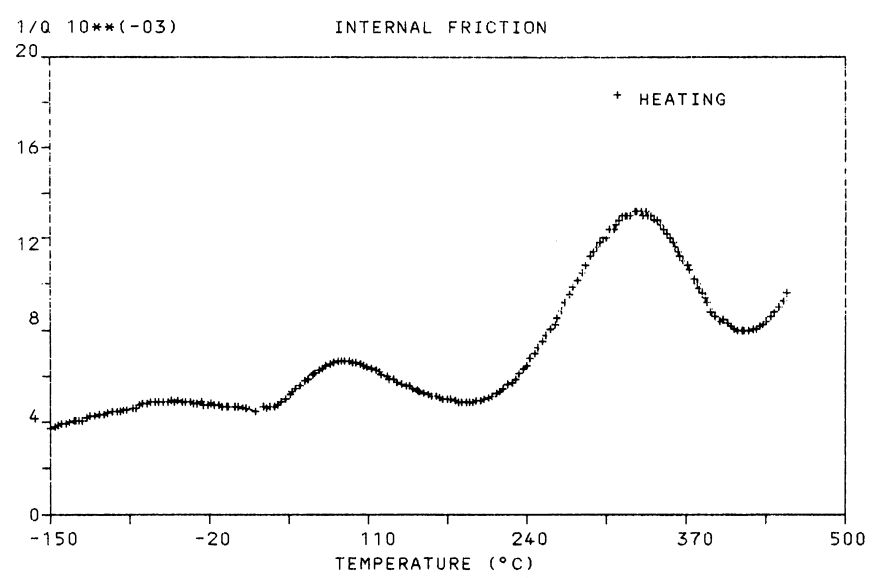

Figure 5. Internal friction of a $28 \%$ heavily deformed $\mathrm{Fe}-30 \mathrm{Mn}-6 \mathrm{Si}-5 \mathrm{Cr}$ specimen.

whilst the peak temperature for the $28 \%$ cold-rolled specimen is raised in comparison with that for the $10 \%$ pre-strained specimen. These give evidence that dislocation relaxation results in the $300^{\circ} \mathrm{C}$ internal friction peak. In addition, the $200^{\circ} \mathrm{C}$ internal friction peak is not found in the $28 \%$ cold-rolled specimen. The absence of the $200^{\circ} \mathrm{C}$ peak indicates that there is no reverse transformation from the stress-induced $\epsilon$-martensite into the parent austenite phase. This can elucidate why the $28 \%$ cold-rolled specimen exhibits no SME character even though it has been reheated to $600^{\circ} \mathrm{C}$.

By applying thermo-mechanical training, the $300^{\circ} \mathrm{C}$ dislocation-relaxation peak is weakened. This can be easily observed from the variation in $\mathrm{Q}^{-1}$ value on the right shoulder of the internal friction spectra shown in Fig. 3, in which the $\mathrm{Q}^{-1}$ value of $300^{\circ} \mathrm{C}$ peak is changed from $4.6 \times 10^{-3}$ for the first cycle to $1.8 \times 10^{-3}$ for the 4 th cycle. It indicates that a large quantity of dislocations could occur in the austenite matrix during the pre-strain deformation. During thermo-mechanical training up to $500^{\circ} \mathrm{C}$, the dislocations would be annealed and hence the $300^{\circ} \mathrm{C}$ peak is weakened. Table 3 displays the yield strength and work hardening exponent of the specimen having different training cycles of 5\% pre-strain. It shows that the yield strength decreases, and the work hardening exponent increases with increasing training cycles. This indicates that the dislocation density is indeed decreased throughout the thermomechanical training. According to the above discussion, thermo-mechanical training can enhance the generation of refined $\epsilon$-martensite and decrease the dislocation density in the parent austenite phase, thus improving the SME.

\section{Conclusions}

The characterization of internal friction and related SME of an Fe-30Mn-6Si-5Cr alloy has been investigated. The internal friction spectra are in fact classified into three peaks, which locate at around

TABLE 3

Effect of Thermo-mechanical Training on the Tensile Properties of Fe-30Mn-6Si-5Cr Alloy

\begin{tabular}{lcccr}
\hline Cyclic training number & 1 & 2 & 3 & 4 \\
\hline Yield strength, $\mathrm{MPa}$ & 410.6 & 377.2 & 371.9 & 370.2 \\
$\mathrm{n}_{2-4}$ & 0.229 & 0.256 & 0.273 & 0.271 \\
\hline
\end{tabular}

Yield strength: $0.2 \%$ offset strength

$\mathrm{n}_{2-4}$ : work hardening exponent under the strain ranging from 2 to $4 \%$ 
$120^{\circ} \mathrm{C}, 200^{\circ} \mathrm{C}$ and $300^{\circ} \mathrm{C}$. The $120^{\circ} \mathrm{C}$ and $200^{\circ} \mathrm{C}$ peaks are ascribed to the reverse transformation of $\alpha^{\prime}$-martensite and stress-induced $\epsilon$-martensite, respectively, into the parent austenite phase. The $300^{\circ} \mathrm{C}$ peak is attributed to the dislocation relaxation found in the austenite matrix. With increasing pre-strain, the maximum height of the $200^{\circ} \mathrm{C}$ peak decreases while that of the $300^{\circ} \mathrm{C}$ peak is sharpened. It reveals that the SME will decrease with increasing pre-strain. Meanwhile, the maximum height of the $200^{\circ} \mathrm{C}$ peak is increased while the peak temperature is decreased after cyclic thermo-mechanical training. These features are in good agreement with the fact that a higher volume fraction of preferentially oriented and refined $\epsilon$-martensite, which can easily reverse transform into the parent austenite phase, has been generated after cyclic thermo-mechanical training. Therefore, the SME is improved.

\section{Acknowledgment}

The authors sincerely acknowledge the financial support of this study by the National Science Council (NSC), Republic of China, under Grants NSC87-2216-E035-009 and NSC88-2216-E002-012.

\section{References}

1. A. Sato, E. Chishima, K. Soma, and T. Mori, Acta Metall. 30, 1177 (1982).

2. A. Sato, E. Chishima, Y. Yamaji, and T. Mori, Acta Metall. 32, 539 (1984).

3. A. Sato, K. Soma, E. Chishima, and T. Mori, J. Phys. C4-797 (1982).

4. M. Murakami, H. Otsuka, H. Suzuki, and S. Matsuda, Trans. ISIJ. 27, B-88 (1987).

5. X. X. Wang and L. C. Zhao, Scripta Metall. Mater. 26, 1451 (1992).

6. T. Moriya et al., Bull. JIM. 29, 367 (1990) (in Japanese).

7. H. C. Lin and K. M. Lin, Scripta Metall. Mater. 34, 343 (1996).

8. H. C. Lin, K. M. Lin, and T. S. Chou, Scripta Metall. Mater. 35, 879 (1996).

9. M. Sade, K. Halter, and E. Hornbogen, Z. Metallkd. 79, 487 (1988).

10. A. Sato, Y. Yamaji, and T. Mori, Acta Metall. 34, 287 (1986).

11. T. Maki and I. Tamura, Proc. ICOMAT-86, JIM, 963 (1986).

12. M. Murakami, H. Otsuka, G. Suzuki, and M. Masuda, Proc. ICOMAT-86, JIM, 985 (1986).

13. A. Sato, K. Takagaki, S. Horie, M. Kato, and T. Mori, Proc. ICOMAT-86, JIM, 979 (1986).

14. H. Tanahashi, T. Maruyama, and H. Kubo, Trans. Mater. Soc. Jpn. 18B, 1149 (1994).

15. K. Tsuzaki, M. Ikegami, Y. Tomota, and T. Maki, ISIJ. 30, 666 (1990).

16. B. H. Jiang, T. Tadaki, H. Mori, and T. Y. Hsu, Mater. Trans. JIM. 38, 1072, 1078 (1997).

17. B. H. Jiang, X. Qi, W. M. Zhou, Z. L. Xi, and T. Y. Hsu, Scripta Metall. Mater. 34, 1437 (1996).

18. S. K. Wu, H. C. Lin, and T. S. Chou, Acta Metall. 38, 95 (1990).

19. H. C. Lin, S. K. Wu, T. S. Chou, and H. P. Kao, Acta Metall. Mater. 39, 2069 (1991).

20. A. Sato, K. Ozaki, Y. Watanabe, and T. Mori, Mater. Sci. Eng. A. 101, 25 (1988).

21. J. T. Lenkkeri and J. Levoska, Phil. Mag. A. 48, 749 (1983). 